\title{
Determinants of Farmland Degradation and its Implication on Crop Productivity and Sustainability
}

\author{
19MENU LETA; "2BIRHANU ITICHA \\ ${ }^{I}$ Department of Agricultural Economics, Assosa University, P. O. Box 18, Assosa, Ethiopia \\ ${ }^{2}$ Department of Soil Resources and Watershed Management, Wollega University, P. O. Box 395, Nekemte, Ethiopia. \\ *Corresponding Author Email: birhanuwu@gmail.com
}

\begin{abstract}
The study analyzed factors influencing smallholder farmland degradation and crop productivity in western Ethiopia. It was done based on survey of 120 households managing a total of 223 farm plots. The survey data was analyzed using ordered probit model. We found that out of 15 explanatory variables investigated, slope of the farm plot, plot distance from homestead, interval of crop rotation, frequency of growing cereal crops, and change in farm plot ownership were found to positively and significantly affect farmland degradation whereas other factors such as household responsibility in the society, livestock holding size, and soil and water conservation practices were found to negatively and significantly influence farmland degradation. The marginal effect of the slope and length of crop rotation interval on probability of the farmland to be classified as degraded land was found to be increased by 7 and $29 \%$, respectively. The regression results show that crop productivity was significantly hampered by improved seeds used, plot size and farmland degradation. Therefore, if the investigated factors get policy merit, it is possible to minimize farmland degradation and enhance agricultural sustainability.
\end{abstract}

\section{DOI: https://dx.doi.org/10.4314/jasem.v22i8.13}

Copyright: Copyright ( $) 2018$ Amenu and Birhanu. This is an open access article distributed under the Creative Commons Attribution License (CCL), which permits unrestricted use, distribution, and reproduction in any medium, provided the original work is properly cited.

Dates: Received: 30 April 2018; Revised: 14 July: 2018; Accepted: 20 August 2018

Keywords: Farm plot; land management; land degradation; crop productivity; sustainability

Farmland degradation is a global phenomenon that affects human societies at the local level where rural communities closely related to land resources are vulnerable. The problem of farmland degradation which results in low agricultural productivity are particularly severe in the rural highlands of Ethiopia that constitute $95 \%$ of cultivable area, that support $88 \%$ of human and $75 \%$ of the livestock population (Holden et al., 2005). The main outcome of land degradation is reduction in the productivity of agricultural output. Cropland productivity loss 0.5 to $1 \%$ per year was estimated suggesting a productivity loss of at least $20 \%$ over the last 40 years compared with a situation without soil degradation (Scherr and Yadav, 1995; Pimentel and Burgess, 2013).

The combined effects of continuous tillage, soil erosion, overgrazing (Lal, 2001; Frankl et al., 2011); other factors such as cultivation of marginal lands, unsustainable use of natural resource, deforestation, unprecedented growth of human and livestock population (Million and Belay, 2004) contributes to farmland degradation. Soil erosion is a root cause of farmland degradation and the most dangerous ecological process in the country (Ludi, 2004). According to FAO (2000), 50\% of the highlands are significantly eroded, of which $25 \%$ are seriously eroded, and $4 \%$ have reached at a point of no return. As a result, the greatest potential for increasing agricultural productivity is likely to come from improved land management practices and efficient application of improved agricultural inputs.

The basic premise for our study was that farmland degradation alters the production function and sustainability of agriculture and induced farmers to convert farmland into lower-value uses. For instance, cropland was converted to fallow/grazing land. Smallholder farmland degradation and crop productivity was determined by complex socioeconomic and physical factors. Thus, the study was aimed at empirical analysis of determinants of farmland degradation and its implication on crop productivity in mixed crop-livestock farming systems. The study helped to screen out the major causes of farmland degradation that hampered agricultural sustainability.

\section{MATERIALS AND METHODS}

Study Site: The study was conducted in Amuru district, Horro Guduru Wollega Zone of Oromia Regional State in Ethiopia with an elevation ranging from 1875 
to $2480 \mathrm{~m}$ above sea level. The district is mainly characterized by steep, undulating, and rolling topography. The average annual rainfall ranges from 1059 to $1792 \mathrm{~mm}$ and mean annual temperatures varies from 14 to $28.1{ }^{\mathrm{O}} \mathrm{c}$. The district has 8,738 household out of which 7,643 were male headed and 1095 were female headed households. Mixed farming system was practiced in the area. The main crops grown include maize (Zea mays), Teff (Eragrostis tef), wheat (Triticum aestivum), and Niger seed (Guizotia abyssinica). The total livestock population in the district is estimated to be 183,440 in number or 49,113 tropical livestock unit (TLU).

Sampling and Attribute Descriptions: Out of a total of 22 Kebeles surveyed in the district, five Kebeles where farmland degradation seemed to be severe were purposively selected for the study. Yemane (1967) formula was employed to determine sample size at 95\% confidence level and $9 \%$ precision as follows:

$$
\mathrm{n}=\frac{\mathrm{N}}{1+\mathrm{N}(\mathrm{e})^{2}}
$$

Where $\mathrm{n}$ : sample size, $\mathrm{N}$ : the total number of household heads and e: level of precision. Accordingly, the formula yielded 115 sample households; however, 120 households (HHs) were used to minimize errors.

Different variables that were expected to affect the level of farmland degradation were assessed including agro-ecology, age in the farming households head, education level of the household head, responsibility of household head in the society, number of livestock in TLU, total number of farm plots, plot size in hectare, plot ownership type, slope of the plot, number of years since the plot developed, average plot distance from the homestead in walking minutes, soil and water conservation, frequency of growing cereal crops on the plot, interval of crop rotation in year, and land use planning. Consecutively, the impacts of level of farm land degradation coupled with other factors such as amounts of UREA and DAP fertilizers used $(\mathrm{kg} / \mathrm{ha})$ and amount of improved seed used (kg/ha) on crop productivity were also investigated.

Econometric Analysis: During the econometric analysis, farmland degradation (dependent variable) and determinants of farmland degradation (independent variables) were used. As the level of land degradation was reported by farm households owning the plots using scale of $0=$ degraded; $1=$ moderately degraded, and 2 = fertile, ordered probit model was used to explain variation in the level of land degradation at a plot and specific crop combination levels as it represents close approximation of the cumulative normal distribution as suggested by (Duncan and Moriarty, 1998).

$$
\begin{aligned}
& Y^{*}=\beta \cdot X i+\varepsilon i \\
& i=1,23, \ldots n
\end{aligned}
$$

Where $\mathrm{Y}^{*}$ is unobserved latent variable for level of farmland degradation (which is ordered), $\beta^{\prime}$ is a vector of coefficient of $X_{i}$ that was estimated, $X_{i}=n$ are explanatory variables, in this sense it represents 15 independent variables, and $\varepsilon_{i}$ is disturbance term.

Initially, the existence of multicollinearity and heteroscedasticity among the hypothesized independent variables were checked. The existence of multicollinearity was tested by using the methods of variance inflation factor (VIF) for continuous explanatory variables and contingency coefficients (CC) for discrete or dummy explanatory variables (Gujarati, 2004). The presence of collinearity among explanatory variables can increases value of VIF. If the VIF was greater than 10 , that variable was said to be highly collinear. Though $\mathrm{CC}$ ranges between 0 and 1 , as rule of thumb, CC values less than 0.5 assumes weak association between discrete explanatory variables and indicates no severe multicollinearity. According to Gujarati (1995), Breusch-Pagan test was used to test heteroscedasticity between $\ln$ transformed variables. Small value of $\chi^{2}$ means that small $p$-value indicating presences of heteroscedasticity problem between independent variables.

According to Gujarati (1995), the generalized form of the Cobb-Douglas (CD) production function was used to examine implication of farmland degradation on crop productivity by analyzing the relationship between factor of input and level of output which can be specified as:

$$
\mathrm{Y}=\mathrm{AX}_{1}{ }^{\beta 1} \mathrm{X}_{2}{ }^{\beta 2} \mathrm{x}_{3}^{\beta 3} \ldots \mathrm{x}_{n}{ }^{\beta n} e^{u i} \text { (3) }
$$

Where, $\mathrm{Y}$ is farm outputs in $\mathrm{kg}$ per ha, $\mathrm{X}_{\mathrm{i}}$ 's are explanatory variables such as plot size, slope, number of year since the plot developed, plot distances from homestead, amount of DAP and UREA used, interval of crop rotation, amount of seed used, dummy of farmland degradation and crop type frequently grown on farm plot, $\beta i$ 's is coefficients/elasticities of output and indicate how strongly each input affects output; A is efficiency parameter and represents the level/state of technology and $U_{i}$ is disturbance term. Logarithmic 
transformation was made to obtain its linear form and to estimate the parameters.

$$
\ln Y=\ln A_{0}+\beta_{1} \ln X_{1}+\beta_{2} \ln X_{2}+\beta_{3} \ln X_{3}--\beta_{n} \ln X_{n}+\text { uif }
$$

where LnY is logarithm of total productivity $(\mathrm{kg} / \mathrm{ha})$, $\ln X_{1}=$ plot size (ha), $X_{2}$ is Slope $(0=$ flat, $1=$ medium, $2=$ steep), $\ln X_{3}$ is number of years the plot was developed, $\ln \mathrm{X}_{4}$ is plot distance from homestead, $\mathrm{X}_{5}$ is dummy farmland degradation, $\ln X_{6}$ is interval of crop rotation (years), $\mathrm{X}_{7}$ is crop type frequently grown on the plot $(0=$ other crop, $1=$ cereal crop $), \ln \mathrm{X}_{8}$ is DAP used $(\mathrm{kg} / \mathrm{ha}), \ln \mathrm{X}_{9}$ is UREA $(\mathrm{kg} / \mathrm{ha}), \ln \mathrm{X}_{10}$ is improved seed $(\mathrm{kg} / \mathrm{ha})$, and $\beta_{0}$ and $\beta_{i}(\mathrm{i}=1,2,3 \ldots, 10)$ are parameters to be estimated. The function was estimated using ordinary least square method.

Statistical Analysis: The SPSS version 20 and STATA version 11 softwares were used to analysis the data and compute VIF and CC. Descriptive statistics such as mean and percentages were used analyze and infer the data. The t-test was used to compare differences between continuous variables while chi-square $\left(\mathrm{x}^{2}\right)$ test was used to compare differences between discrete/dummy variables.

\section{RESULTS AND DISCUSSION}

Socio-Economic and Farmland Characteristics: The survey result showed that an average age in the 120 HHs (109 male and 11 female) interviewed was nearly 43 years. The average farming experience of the sampled HHs was nearly 19 years though it lied between 3 and 48 years. The number of farm plots per $\mathrm{HH}$ varied from one to four. Majority of the sampled HHs $(42.5 \%)$ have two plots. Only four out of the total sampled HHs contain four farm plots. Plot size ranged between 0.25 and 6 hectares. Majority (46\%) of the HHs owned plot size between 3 and 4 hectares. The results show that out of 223 farm plots surveyed, 186, 14,12 and 11 plots were classified under owned, rentin, rent-out and shared cropping, respectively. Out of the 29 severely degraded plots, nine plots were occurred among the shared cropping and five were among the owned farm plots. Out of 73 non degraded farm plots surveyed, 71 plots were among the owned plots. This indicated that own farm plots improve soil fertility than rent-in, rent-out and shared cropping systems. Close to $60.7 \%$ of highly degraded farm plots were found in the steep slopes. Nearly $90 \%$ of the total farm plots were found at distance less than 15 walking minutes from homestead.

Determinants of Farmland Degradation: The impacts of 15 different variables on the farmland degradation were assessed immensely. The data presented in Table 1 indicates that there was no multicollinearity problem for each continuous variable because the values of VIF were less than 10. Similarly, Table 2 showed that multicollinearity was not a serious problem between discrete and dummy independent variables because $\mathrm{CC}$ was less than 0.5 .

Table 1: Variance inflation factor (VIF) for continuous independent variables

\begin{tabular}{lll}
\hline Coefficients & \multicolumn{2}{c}{ Collinearity statistics } \\
\cline { 2 - 3 } & VIF & Tolerances \\
\hline NYPD & 1.87 & 0.53 \\
PtSi & 1.55 & 0.64 \\
TLU & 1.43 & 0.69 \\
AgeHH & 1.32 & 0.75 \\
PNo & 1.18 & 0.84 \\
PD & 1.10 & 0.90 \\
ICR & 1.10 & 0.91 \\
\hline
\end{tabular}

AgeHH: age in farming household head, TLU: number of livestock in tropical livestock unit, PNo: total number of farm plots, PtSi: plot size in hectare, NYPD: number of year since the plot developed, PD: average plot distance from the homestead in walking minutes, ICR: interval of crop rotation in year. AgrEco: agro-ecology, EduHH: education level of household head, RHH: responsibility of household head in the society, POW: plot ownership type, Slop: slope of the plot, SWC: soil and water conservation, FGCC: frequency of growing cereal crops on the plot, LUP: land use planning.

\begin{tabular}{lllllllll}
\multicolumn{10}{l}{ Table 2: Contingency coefficients (CC) for discrete and dummy independent variables } \\
\hline Variable & AgrEco & EduHH & RHH & POW & Slop & LUP & SWC & FGCC \\
\hline AgrEco & 1.00 & 0.17 & 0.02 & 0.10 & 0.19 & 0.09 & 0.03 & 0.09 \\
EduHH & & 1.00 & 0.36 & 0.29 & 0.33 & 0.10 & 0.17 & 0.19 \\
RHH & & & 1.00 & 0.14 & 0.15 & 0.06 & 0.07 & 0.09 \\
POW & & & & 1.00 & 0.16 & 0.03 & 0.31 & 0.15 \\
Slop & & & & & 1.00 & 0.07 & 0.24 & 0.17 \\
LUP & & & & & & 1.00 & 0.23 & 0.23 \\
SWC & & & & & & & 1.00 & 0.21 \\
FGCC & & & & & & & & 1.00 \\
\hline
\end{tabular}

Table 3: The maximum livelihood estimates of the ordered probit model

\begin{tabular}{llllcc}
\hline \multirow{2}{*}{ Variable } & \multirow{2}{*}{ Coefficient } & $\mathrm{P}[|\mathrm{Z}|>\mathrm{z}]$ & & \multicolumn{3}{c}{ Marginal effect } \\
\cline { 4 - 5 } \cline { 3 - 5 } & & & $\mathrm{Y}=0$ & $\mathrm{Y}=1$ & $\mathrm{Y}=2$ \\
\hline
\end{tabular}




\begin{tabular}{llllrr}
\hline Constant & 1.948 & 0.002 & 0.023 & 0.693 & 0.283 \\
AgrEco & 0.427 & 0.105 & -0.023 & -0.122 & 0.145 \\
AgeHH & 0.018 & 0.214 & -0.001 & -0.005 & 0.006 \\
EduHH & -0.107 & 0.286 & 0.006 & 0.030 & -0.036 \\
RHH & $-0.585 * *$ & 0.047 & -0.028 & -0.176 & 0.205 \\
TLU & $-0.894 * *$ & 0.011 & -0.355 & -0.203 & 0.151 \\
PNo & -0.070 & 0.683 & 0.004 & 0.019 & -0.024 \\
PtSi & -0.058 & 0.663 & 0.003 & 0.016 & -0.019 \\
POW & $0.362 * *$ & 0.035 & 0.020 & 0.103 & 0.123 \\
Slop & $1.264 * * *$ & 0.000 & 0.070 & 0.358 & -0.428 \\
NYPD & -0.008 & 0.440 & 0.0004 & 0.002 & -0.003 \\
PD & $0.068 * * *$ & 0.006 & 0.027 & 0.021 & -0.057 \\
SWC & $-0.532 *$ & 0.067 & -0.035 & -0.137 & 0.172 \\
FGCC & $0.464 *$ & 0.082 & 0.029 & 0.120 & -0.150 \\
ICR & $0.538 * *$ & 0.02000 & -0.029 & -0.152 & -0.183 \\
LUP & -0.073 & 0.886 & 0.003 & 0.0234 & -0.026 \\
\hline 120; LR chi $^{2}(15)=59.17 ;$ Prob $>$ chi ${ }^{2}=0.00 ;$ Pseudo $R^{2}=0.28 ;$ Log likelihood $=-76.92$ \\
***, ** and $*$ are significant at 1,5 and $10 \%$ probability level, respectively.
\end{tabular}

Out of 15 variables studied, eight of them were found to significantly affect farmland degradation at different significance levels (Table 3). Nearly 15, 58.7 and $26 \%$ of farm plots surveyed were found to be degraded, moderately degraded, and non-degraded, respectively. Positive estimated coefficients in the model imply increased farmland degradation with increased in the value of the independent variables. Whereas negative estimated coefficient in the model implies decreasing severity of farmland degradation with increased value of the independent variables. The marginal values indicated the impact of a unit change in the individual independent variables on farmland degradation when all other variables were held at their means.

Factors Positively Affecting Farmland Degradation: Our results showed that slope of the farm plot, plot distance from homestead, interval of crop rotation, frequency of growing cereal crops, and change in farm plot ownership from own plot to other forms were found to positively and significantly related to farmland degradation as depicted from ordered probit model coefficient estimate for these variables (Table $3)$. These factors apparently reduced agricultural sustainability. The finding of the study showed that slope of the farm plot was the most significant determinant of farmland degradation at $1 \%$ level of significance. Owing to over population and limitation of farm plots, farmers in the study area were usually cultivating steep slopes. Our results show that as degree of slope of the farmland increases from one rank to the next (flat to moderate and then to steep slope), the marginal effect of the slope on probability of the farmland to be classified as degraded and moderately degraded land will be increased by 7 and $35.8 \%$, respectively; while that of being classified as non degraded land will be decreased by $42.8 \%$. Getachew (2005) suggested that increase in degree of slope increases probability of the farmland to be classified as degraded land. This could be because slope steepness coupled with traditional nature of tillage practices had created suitable condition for soil erosion.

Farm plot distance from the homestead was positively and significantly affected farmland degradation at $1 \%$ probability (Table 3 ). Our results indicate that with one unit increase in the distance of the farm plot from the homestead in walking minute, the probability of the plot being classified as fertile land will be decreased by about $5.7 \%$ whereas the probability of the plot being classified as degraded land will be increased by about $2.7 \%$. Management of agricultural inputs and outputs were relatively difficult for distant farm plots than those located nearest to homesteads. For instance, chance of obtaining organic fertilizers (animal manures), timely weeding, immediate response to crop diseases and pests, application of SWC measures, frequent supervision from wild animals was very minimal for distant plots. Researchers also reported that the farther the farms were to the farmer's home, monitoring becomes less frequent (Huffman and Fukunaga, 2008) and decision could be perhaps related to the availability of resource and profitability of the conservation structures (Wagayehu and Drake, 2003).

We found that increase in the length of crop rotation interval aggravates farmland degradation and depletes soil fertility. With change in length of crop rotation interval from yearly based to four years interval, the probability of the farmland to be classified as degraded land will be increased by about $29 \%$ while chance to be classified as fertile land will be decreased by $18.3 \%$. This shows that yearly based crop rotation (cereals with legumes) minimized farmland degradation better than crop rotations that happen after 2-4 years. This could be because it enhances nitrogen status of the soil. The present study results 
corroborates the findings of Meindertsma (1997) who revealed that long year interval of crop rotations result in low soil fertility status and favor building up of pests and diseases both in the soil and crops. Frequency of growing cereal crops also positively affected farmland degradation. With increase in frequency of growing cereal crops on farm plot, the probability of the farm plot being classified as degraded land will be increased by about $2.9 \%$. Due to scarcity of farmland, farmers having small plot size were forced to successively grow cereals (maize and teff), the major staple food crops, on same plot. Cereal crops were found to reduce soil nutrient as they exhaustively mine nutrients from the soil. Benin et al. (2004) indicated that frequent growing of one cereal crop may have opposing effects on another crop and encourages land degradation.

The present study results indicated that own managed plots tend to be less degraded than rented or share cropped plots. When plot ownership type changed from own to rented plot, the probability of the plot to be classified as degraded land will be increased by about $2 \%$. This might be because farmers who have no own farm plot and whose livelihood depend on shared or rented cropping system were not interested to invest on sustainable land management practices such as compost, SWC, fallowing, and other measures. This was related to the issue of land security. Our results were consistent with the findings of Dione (2002) who reported that in case of African land ownership systems; farmland held-under owned land is more productive than farmland under other forms of ownership type.

Factors Negatively Affecting Farmland Degradation: We found that household responsibility in the society, livestock holding size, and SWC practices were found to negatively and significantly affect farmland degradation (Table 3). These were factors that improved agricultural sustainability. Our results indicate that increased household heads' responsibility in the society had reduced farmland degradation. The marginal effect of responsibility of farmers in the society on the farmland degradation showed that with increase in responsibility of household heads in the society, the probability of the farmland to be classified as degraded land will be decreased by about $2.8 \%$ and as fertile land will be increased by about $20.5 \%$. This might be because farmers who had some representative roles in the society got exposure to different sources of information such as trainings and exposure visits. For instance, skill development trainings on sustainable land management practices were often provided to the community leaders and model farmers. As a result, they were more informed than average farmers about techniques of minimizing land degradation. The specific result is contrary to the finding of Getachew (2005).

So far, there was a premise that large livestock size degrades land through overgrazing and trampling over the surface. In contrast, our findings indicated that as the numbers of livestock holding in TLU increases, the status of farmland degradation decreases. With one unit increase in TLU, the probability of the farm plot being classified as degraded land will be decreased by about $35.5 \%$. This could be because farmers who had more livestock were able to improve their plot by application of manures at a time. A farmer who had small number of livestock got little amount of manures and his farm plots remains untreated by manures. This was consistent with the findings of Pender et al. (2003) that size of livestock holding is an important determinant of farmers' behavior to improve soil fertility of croplands through manuring and more capital investment on SWC measures. However, the present study results were contrary to Liverpool and Winter-Nelson (2000) who suggested that livestock density on farm causes disturbance of the topsoil and vegetation leading to increased land degradation.

Our study results also shows that implementation of SWC practices had decreased the severity of farmland degradation. Practicing SWC measures on the farm plot increases a chance of the plot to be classified as non degraded land by about $17.2 \%$. The SWC measures also created suitable condition for plantation of trees that were used to improve soil fertility. A survey conducted by Hamado (2011) indicated that farmer innovators who use SWC technologies regenerate and protect more trees than non-innovator farmers. In line with our results, a study report by Wagayehu and Drake (2003) in the eastern Ethiopian highland at Hunde-Lafto area indicated that investing in SWC measures have positive impacts in terms of mitigating land degradation and improving farm household's food production and income.

Implication of Farmland Degradation on Crop Productivity: Our findings indicated that there was no serious problem of heteroscedasticity in the model because estimated $\mathrm{p}$-value was greater than $10 \%$ significance level $(p=0.829)$. As observed from the value of adjusted coefficient of multiple determinations (Table 4), only $68 \%$ of variation in crop productivity explained by variation in the independent variables was included in the model. Cobb-Douglass production analysis showed that three out of ten independent variables tested were significantly influenced crop productivity and agricultural sustainability (Table 4 ). These variables 
were plot size cultivated, farmland degradation, and improved seed used.

Table 4: Factors explaining crop productivity (kg/ha) (plot level analysis by crop type)

\begin{tabular}{|c|c|c|c|c|c|}
\hline \multirow[t]{2}{*}{ Explanatory Variables } & \multicolumn{5}{|c|}{ Coefficient } \\
\hline & Maize & Teff & Wheat & Niger Seed & All plots \\
\hline Plot size (ha) & $-1020.59 * * *$ & 4.47 & 132.45 & -150.26 & $-442.85 * * *$ \\
\hline Slope $(0=$ flat, $1=$ medium, $2=$ steep $)$ & 25.20 & -43.06 & 8.46 & 115.02 & 51.24 \\
\hline No. of years the plot was developed & 2.96 & 1.33 & -4.15 & -0.48 & -0.81 \\
\hline Plot distance from homestead & -15.77 & 0.01 & -8.44 & 7.15 & -3.60 \\
\hline Dummy_ Medium degradation & 40.65 & $288.43 * *$ & $526.81 * *$ & 192.82 & $241.02 *$ \\
\hline Dummy-_No degradation & 265.36 & $407.27 * * *$ & 366.40 & 318.29 & $368.87 * *$ \\
\hline $\mathrm{DAP}(\mathrm{kg} / \mathrm{ha})$ & 0.78 & 0.34 & 3.59 & 0.88 & 0.75 \\
\hline Urea $(\mathrm{kg} / \mathrm{ha})$ & 1.50 & -2.80 & 2.98 & -5.35 & $1.63 *$ \\
\hline $\begin{array}{l}\text { Dummy_if cereals are frequently grown on } \\
\text { the plot }(1=\text { yes })\end{array}$ & -338.23 & 61.11 & -111.94 & 71.42 & -47.10 \\
\hline Interval of crop rotation (year) & -200.80 & -11.09 & -8.89 & 20.47 & -45.90 \\
\hline Used improved seed (1=yes) & $866.26 * *$ & $870.08 * * *$ & 453.36 & 307.45 & $919.61 * * *$ \\
\hline Dummy_Teff & & & & & $-650.87 * * *$ \\
\hline Dummy_Wheat & & & & & $-605.66^{* * *} *$ \\
\hline Dummy_Niger seed & & & & & $-554.46^{* *}$ \\
\hline Constant & $2518.93 * *$ & 341.8662 & 335.39 & 189.42 & $1495.17 * * *$ \\
\hline Number of obs. & 73 & 61 & 33 & 40 & 212 \\
\hline F-Value & 3.98 & 4.86 & 2.91 & 0.46 & 30.86 \\
\hline Prob $>$ F & 0.0002 & 0.000 & 0.017 & 0.914 & 0.000 \\
\hline R-squared & 0.418 & 0.522 & 0.604 & 0.153 & 0.703 \\
\hline Adj R-squared & 0.313 & 0.414 & 0.396 & -0.181 & 0.680 \\
\hline
\end{tabular}

Farmers who operate a larger cultivated area did not be able to carry out important agricultural operations such as planting, cultivation, weeding timely and as a result, crop productivity decline. We found that variation in plot size cultivated was found to significantly influence variation in maize productivity at $1 \%$ level of significance. The elasticity estimate of maize was -1020.59 with respect to the area of cultivated land. This implies that other things being constant; a $1 \%$ increase in the area of cultivated land was associated with $1020.59 \%$ decrease in maize productivity. Presence of inverse relationship between farm size and land productivity was reported by Byiringiro and Reardon (1996). Similarly, the status of farmland degradation was found to significantly influence crop productivity. Degraded farm plots produced fewer yields than fertile plots. The coefficient of dummy variable for farmland degradation was varying in magnitude between main crops. When analyzing implication of farmland degradation on crop productivity and sustainability, we compared Teff productivity on nondegraded/fertile land with Teff productivity on degraded land, but not Teff productivity with that of maize productivity. The productivity of Teff on nondegraded/fertile farm plot was 407.27 times higher than on degraded farm plot at $1 \%$ level of significance (Table 4). The productivity of Teff on moderately degraded farm plot was 288.4 times higher than same crop productivity on degraded plot at $5 \%$ probability level. Non degraded or fertile plot increases productivity of main crops by 368.87 times higher than that of degraded plots at 5\% significance level. Niger seed productivity was not affected by any of the included variables. This might be because Niger seed has high potential in fixing nitrogen as compared to cereal crops. It was similar to the findings of Egbetokun et al. (2014) who suggested that farmlands with no degradation problem were more productive than farmlands with severe degradation problem. Crosson (1997) also suggested productivity loss rate of $50 \%$ for severely degraded farm plot. Use of improved seeds had also significant impact on crop productivity. Farmers who use improved seeds of maize and Teff increased productivity by 866.26 and 870.08 times higher than non-users. Therefore, improved varieties are more productive than local varieties; as also suggested by Tuong (1999).

Conclusions: The study examined determinants of farmland degradation and its implication on agricultural productivity and sustainability. Out of many factors studied, household head in the society, livestock holding size, slope of the farmland, farmland ownership type, plot distances from homestead, interval of crop rotation, soil and water conservation practices and crop type frequently grown were found to significantly affect farmland degradation. Similarly, plot size, the status of farmland degradation and improved seed used were found to strongly affect productivity of main crops. An attempt to minimize farmland degradation and improve crop productivity need to avoid cultivation of steep slopes, ensure land security, practice soil and water conservation 
measures and other best practices. None of the plots inappropriately cultivated by smallholder farmers were productive and sustainable.

\section{REFERENCES}

Amede, T; Belachew, T; Geta, E (2001). Reversing the Degradation of Arable Land in Ethiopian Highlands. Managing African Soils No. 23. London.

Benin, S; Smale, M; Pender, J; Gebremedhin, B; Ehui, $S$ (2004). The economic determinants of cereal crop diversity on farms in the Ethiopian highlands. Agric. Econ 31(2-3): 197-208.

Byiringiro, F; Reardon, Th (1996). Farm productivity in Rwanda: effects of farm size, erosion, and soil conservation investments. Agric. Econ 15(2): 127-136.

Crosson, P (1997). Will Erosion Threaten Agricultural Productivity? Environ: Sci. Policy Sustain Dev 39(8): 4-31.

Dione, J (2002). Land tenure systems and their implication for food security and sustainable development in Africa. pp. 132-133. Proceedings of a conference on policies for sustainable land management in the East African highlands. IFPRI and ILRI, Addis Ababa, Ethiopia.

Duncan, T; Moriarty, SE (1998). A CommunicationBased Marketing Model for Managing Relationships. J. Mark 62(2): 1-13.

Egbetokun, A; Oluwatope, O; Adeyeye, D; Sanni, M (2014). The role of industry and economic context in open innovation: Evidence from Nigeria. UNU-MERIT Working Paper Series. Keizer Karelplein 19, 6211 TC Maastricht, The Netherlands.

FAO (2000). Management of degraded soils in Southern and East Africa. Rome, Italy.

Frankl, A; Nyssen, J; De Dapper, M; Mitiku, H; Deckers , J; Poesen, J (2011). Trends in gully erosion as evidenced from repeat photography (North Ethiopia). Landform Analys 17: 47-50.

Getachew, A (2005). Determinants of Land Degradation in the Lake Tana Basin and its Implications for Sustainable Land Management: The Case of Angereb and Gishe Abbay Watersheds [MSc thesis]. Haramaya, Ethiopia: Haramaya University.
Gujarati, DN (1995). Econometrics, $3^{\text {rd }}$ ed. McGrawHill, Inc., New York.

Gujrati, DN (2004). Basic Econometric, (4th Ed.). The McGraw-Hill Companies. NewYork.

Hamado, S (2011). Using soil and water conservation techniques to rehabilitate degraded lands in northwestern Burkina Faso. Int. J. Agric. Sustain 9(1): 120-128.

Holden, ST; Lofgren, H; Shiferaw, B (2005). Economic Reforms and Soil Degradation in the Ethiopian Highlands: A Micro CGE Model with Transaction Costs. International Conference on Policy Modeling, Norway, pp. 1-25.

Huffman, W; Fukunaga, K (2008). Sustainable land use: landlord-tenant contracting in the United States of America. NJAS - Wageningen J. Life Sci 55: 379-396.

Lal, R. (2001). Soil degradation by erosion. Land Degrad. Dev 12(6) 519-539.

Liverpool, S; Winter-Nelson, A (2000). Asset versus Consumption Poverty and Poverty Dynamics in the Presence of Multiple Equilibrium in Rural Ethiopia. IFPRI Discussion Paper 00971.

Ludi, E (2004). Economic Analysis of Soil Conservation: Case Studies from the Highlands of Amhara Region, Ethiopia: African Studies Series A18. Geographical Bernensia, Bernee.

Meindertsma, JD (1997). Income diversity and farming systems: Modelling of farming households in Lombok, Indonesia. Royal Tropical Institute, 1095 HA Amsterdam, Netherlands.

Million, T; Belay, K (2004). Factors influencing adoption of soil conservation measures in southern Ethiopia: The Case of Gununo Area. J. Agr. Rural Dev. Trop 105(1): 49-62.

Pender, JL; Nkonya, E; Jager P; Sserunkuuma, D; Ssali, H (2004). Strategies to increase agricultural productivity and reduce land degradation. Agric. Econ 31: 181-195.

Pimentel, D; Burgess, M (2013). Soil Erosion Threatens Food Production. Agric 3(3): 443463. 
Scherr, SJ; Yadav, S (1995). Land degradation in the developing world: implications for food, agriculture, and the environment to 2020. In Food agriculture and the environment discussion paper 14. International Food Policy Research Institute, Washington.

Storck, H; Berhanu, A; Bezabih, E; Birowiecki, A; Shimelis, WH (1991). Farming Systems and Farm Management Practices of Small Holders in the Hararghe Highlands. Farming Systems and Resource Economics in the Tropics, Vol. II, Wissenschafts Vavk Kiel, Germany.
Tuong, TP (1999). Productive water use in rice production: opportunities and limitations. J. Crop Prod 2: 241-264.

Wagayehu, B; Drake, L (2003). Soil and Water Conservation Decision Behavior of Subsistence Farmers in the Eastern Highlands of Ethiopia: A Case Study of the Hunde Lafto Area. Ecol. Econ 46(3): 437-451.

Yamane, T (1967). Statistics: An introductory Analysis, $2^{\text {nd }}$ edition, New York. 